\title{
LÍMITES DE LA PROMOCIÓN RURAL EN EL PAÍS VASCO TRAS DOS DÉCADAS DE PROGRAMAS DE DESARROLLO RURAL
}

\author{
Juan Cruz Alberdi Collantes \\ Departamento de Geografía. Facultad de Letras de la Universidad del País Vasco \\ juancruz.alberdi@ehu.eus
}

\section{RESUMEN}

El año 1998 el Gobierno Vasco pone en marcha un modelo de desarrollo rural fundamentado en la colaboración entre administraciones locales y regionales. Su objetivo es profundizar en la transversalidad de las acciones y garantizar la sostenibilidad económica y social de las comunidades rurales. Generan herramientas de actuación y de organización para un modelo inédito y destacado por las nuevas expectativas que crea. Tras casi dos décadas de funcionamiento los agentes rurales continúa reivindicando la valía de la propuesta pero las actuaciones no han dado los resultados esperados. La falta de implicación administrativa ha sido notoria y el modelo se ha ido vulgarizando hasta asimilarse al de otras regiones de España.

Palabras clave: planificación rural; desarrollo rural; País Vasco; medio rural; grupos de acción local.

\section{ABSTRACT}

\section{Limits of rural development in the Basque Country after two decades of rural development programmes}

In 1998 the Basque Government launched a model of rural development based on collaboration between local and regional administrations. The aim was to increase the mainstreaming of the actions, ensuring economic and social sustainability of rural communities. The model generated new tools of action and organization and the Basque rural community highlighted the validity of the model. After nearly two decades of operation, rural facilitators continue vindicating the worth of the proposal but its application has not had the expected results. The main problem has been the lack of administrative involvement and the model has been diluted to become similar to those of other regions of Spain.

Key words: rural planning; rural development; Basque Country; rural area; local action groups

\section{INTRODUCCIÓN}

A finales de los noventa las instituciones vascas ponen en marcha una nueva iniciativa de desarrollo rural fundamentada en las posibilidades que la orientación y la coordinación de las administraciones públicas pueden aportar al desarrollo rural. Con la aprobación de la Ley de Desarrollo Rural del País Vasco (1998) las instituciones y agentes rurales realizaron los primeros Programas de Desarrollo Rural [PDR] de las comarcas del País Vasco.

Las actualizaciones posteriores (2007 y 2016) de los PDR constituyen un ejercicio de reflexión que deja en evidencia la fragilidad del documento legal y esboza la necesidad de plantear un nuevo modelo de actuación en materia de desarrollo rural, menos pretencioso, más realista y apoyado en los medios que tienen los agentes de desarrollo. Estos instrumentos constituyen un reflejo de las aspiraciones, pero también de las posibilidades con las que agentes y programas de desarrollo rural cuentan actualmente. Centramos la investigación en el análisis de la evolución de contenidos y metodología empleada en los 
diferentes programas de desarrollo rural y en los resultados que en cada momento el modo de proceder ha ido aportando ${ }^{1}$.

\subsection{Punto de partida: el fracaso de un modelo de promoción ${ }^{2}$}

La Ley de Desarrollo Rural del País Vasco (1998) es un documento ambicioso, aprobado por unanimidad, refrendado por los agentes sociales y cuyo objeto es el de definir los objetivos que deben orientar las actuaciones de las administraciones públicas en materia de desarrollo rural. Propone el establecimiento del marco normativo en el que se han de apoyar las políticas orientadas de manera específica al progreso de las zonas rurales y determina los instrumentos que permitan adecuar el resto de políticas y actuaciones administrativas con la consecución de los objetivos del desarrollo rural que se establecen en la Ley.

El modelo organizativo que plantea la Ley de Desarrollo Rural se apoya en programas de desarrollo rural. En su elaboración las instituciones eligen la comarca como ámbito preferente de actuación, por la convicción de que el nivel comarcal se muestra como el más adecuado para emprender tal labor, un espacio cohesionado, con una relación funcional manifiesta y con una problemática socioeconómica similar.

Entre la asunción de competencias cabe resaltar la necesidad de que tanto el Gobierno Vasco como las diputaciones y ayuntamientos han de participar en la elaboración de los Planes de Desarrollo Rural puesto que su aprobación lleva implícita una obligatoriedad de aceptación y de ejecución en el ámbito competencial de cada institución.

Las labores de coordinación y colaboración entre las distintas instituciones las ejerce Landaberri, en cuyo seno se produce la cooperación y colaboración necesarias para la aplicación de la presente ley. Está adscrito al Gobierno Vasco, recayendo la presidencia y la responsabilidad de coordinación en el área de Agricultura y Desarrollo Rural. Está formada por representantes del Gobierno Vasco, las Diputaciones Forales y los municipios del País Vasco ${ }^{3}$. Cada provincia, al mismo tiempo, ha de constituir su propia Landa territorial.

Si Landaberri es el órgano que ha de cumplir la función de coordinar y dirigir las actuaciones en materia de desarrollo rural, la aplicación de los programas diseñados en cada comarca es realizada por órganos locales. En este sentido, la Ley apuesta por la creación de una nueva figura, las Asociaciones de Desarrollo Rural [ADR], que se establecen como instrumento de participación y colaboración de los agentes económicos y sociales en las actuaciones de desarrollo rural. La Ley establece los requisitos para el reconocimiento de las ADR con el carácter de entidades representativas de los diferentes sectores económicos y sociales de la zona comprendida en un PDR. Las ADR vienen a dar continuidad a la labor de los grupos de acción local creados a raíz de la Ley de Agricultura de Montaña de 1986 y que en la Comunidad Autónoma Vasca participaban en la gestión del programa Leader y 5B.

El mismo año en que es aprobada la Ley de Desarrollo Rural, Landaberri encarga la elaboración de los programas de desarrollo rural, de aquellos que coinciden con las comarcas que se benefician de los programas de la iniciativa Leader II y dos años después del resto de las comarcas del País Vasco. La gran mayoría del territorio se beneficia de la aplicación de estos programas (Ver mapa 1) ${ }^{4}$.

1 Esta investigación es fruto de en un proyecto de colaboración entre el Departamento de Geografía de la Universidad del País Vasco y las Asociaciones de Desarrollo Rural del País Vasco, dirigido por el redactor de este trabajo, con el código OTRI 2006.003

2 Resumimos en este apartado, punto de partida de la investigación, las conclusiones obtenidas en una investigación previa, que el autor publica en el año 2004 y cuya consulta es recomendable para aquel investigador que desee profundizar en las particularidades que este documento legal aporta al desarrollo rural.

3 Entre sus funciones cabe destacar la obligatoriedad que tiene de informar sobre las propuestas que se hagan en los Planes de Desarrollo Rural previamente a su elaboración, al mismo tiempo que se le ha de informar sobre aquellos proyectos de ley, decretos, planes o programas de instituciones públicas que afecten de manera importante a las zonas recogidas en los PDR, reservándose el derecho de vetarlas si los miembros de Landaberri así lo decidieran. De igual modo, le compete formular y proponer recomendaciones e iniciativas en torno a la ejecución de los PDR. Landaberri es la encargada de elaborar los programas de desarrollo rural, labor que la realiza a partir de la entidad responsable de la coordinación del desarrollo rural en la Comunidad Autónoma Vasca, Mendikoi, entidad que ya ha acometido la dirección y ejecución de los diferentes programas Leader.

4 Todas las comarcas del País Vasco, excepto el Gran Bilbao y el municipio de Vitoria, son objeto de un pormenorizado análisis de su medio rural (Ver mapa 2). El año 1998 se realizan los correspondientes a las comarcas de Enkarterrialde, Cantábrica Alavesa, Estribaciones del Gorbea, Valles Alaveses, Montaña Alavesa, Llanada Alavesa, Tolosaldea-Urola Kosta y Arratia-Nervión. En el año 2000 se inicia la redacción de los Planes de las comarcas de Durangoaldea, Uribe, Busturialdea, Lea-Artibai, Debabarrena, DonostialdeaBidasoa, Goierri y Debagoiena. En las posteriores revisiones todas ellas se acometerán en el mismo periodo de tiempo. 


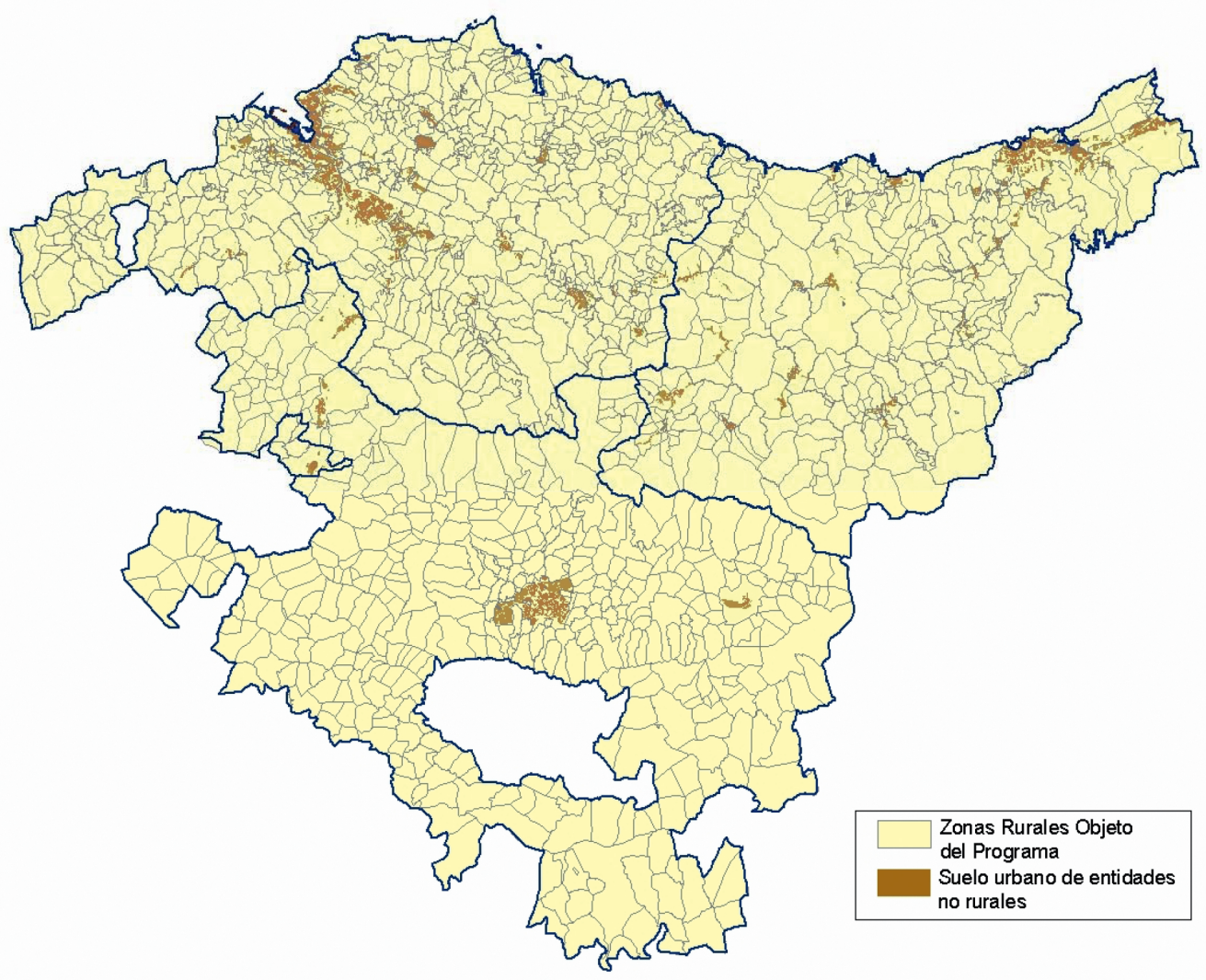

Fuente: Gobierno Vasco Departamento de Agricultura, Pesca y Alimentación (2014).

Teniendo en cuenta que se trata de un programa integral, realizado bajo la consideración de que el desarrollo rural requiere de actuaciones que incidan sobre los distintos aspectos que condicionan la actividad y la calidad de vida en el medio rural (actividad económica, vivienda, equipamientos y servicios, infraestructuras, medio ambiente, etc....), a lo largo del proceso las instituciones responsables promueven la participación de agentes representativos de los distintos ámbitos objeto de análisis. Por todo ello, se define un sistema de participación basado en la configuración de diversos grupos de trabajo capaces de aportar las distintas visiones que hacen posible un diseño completo del desarrollo del medio rural de la comarca. Son unos planes participativos, abiertos al conjunto de los habitantes del medio rural, y ambiciosos, en la medida en que pretenden abarcar todos aquellos aspectos que condicionan el progreso de este medio.

Sin embargo, las perspectivas generadas a raíz de la aprobación de la Ley de Desarrollo Rural en términos generales no se han cumplido. En las reflexiones efectuadas por los agentes rurales ${ }^{5}$ el aspecto más criticado es la falta de compromiso económico adquirido que respalde los PDR. Es más, según ellos, la política desarrollada no responde a las prioridades establecidas en los planes de desarrollo rural.

Los responsables de los programas tienen la convicción de que los PDR no han sido asumidos como una herramienta de utilidad cotidiana. Se observa que ni la administración ni los agentes sociales dan a la Ley y a los PDR la importancia que realmente tienen o pueden tener. En este sentido, apuntan falta de consenso político, a pesar de que fue aprobada por unanimidad, falta de credibilidad en lo que señala tanto la Ley como los PDR, inexistencia de coordinación entre los distintos niveles de la administración.... En definitiva, una falta de interiorización de la importancia que posee llevar adelante el desarrollo del medio rural y con ello, un desánimo generalizado entre entidades locales y Asociaciones de Desarrollo

5 Los resultados de las jornadas se recogen en un informe interno titulado "Ley de Desarrollo Rural y Programas de Desarrollo Rural. Jornadas de reflexión 14,15,18 y 24 de Julio de 2003", organizadas por Mendikoi y el área de Desarrollo Rural del Gobierno Vasco. 
Rural, que se sienten protagonistas débiles en el cumplimiento de la función para la que, al menos estas últimas, fueron creadas.

Dos décadas después del inicio de los primeros programas de desarrollo rural, a pesar de la vigencia del documento legal, ni se ha conseguido implicar Administraciones y Departamentos diferentes a los agrarios ni las entidades diseñadas han iniciado su andadura. Permanece el interés y la ayuda económica de la administración sectorial, la organización comarcal, la coordinación territorial (antes Mendikoi, ahora $\mathrm{Hazi}^{6}$ ) y los Planes de Desarrollo Rural pero la coordinación interadministrativa no se ha iniciado y la implicación departamental no ha avanzado.

\subsection{Objetivo e Hipótesis: testar la validez de un modelo precursor}

Para entender el objeto de la investigación contextualizamos las peculiaridades del modelo de desarrollo rural vasco. A diferencia de muchas regiones del Sur de Europa, el País Vasco apenas ha obtenido fondos de desarrollo regional y rural de origen comunitario ${ }^{7}$. En materia de desarrollo rural, por ejemplo, las dos últimas décadas tan sólo ha contado con un único grupo Leader, Mendinet, que ha dirigido sus esfuerzos a financiar la promoción de negocios privados y la creación de infraestructura turística pública en las zonas más rurales del País Vasco. Esta labor se veía completada por el Plan de Desarrollo Rural Sostenible del País Vasco [PDRs] que, cofinanciado por Europa, mediante el capítulo IV del noveno eje, apoyaba preferentemente inversiones de carácter urbanístico de las entidades locales más rurales (mejora de calidad de vida).

La falta de dotación presupuestaria no ha influido en la ordenación de sus estructuras. Las zonas rurales llevaban organizándose desde mediados de los ochenta en Asociaciones de Agricultura de Montaña, estructuras comarcales en las que agentes locales proponían programas anuales de desarrollo rural, que eran cofinanciados por las Diputaciones Forales ${ }^{8}$.

Esta estructura organizativa sufre un salto cualitativo a finales de la década de los noventa, una vez que el Gobierno Vasco y las Diputaciones deciden llevar adelante una política de desarrollo fundamentada en las posibilidades y responsabilidades que cada Departamento tenía (sanidad, infraestructuras, educación, agricultura, industria...). Cambia el modo de hacer, el objetivo, pero la organización se sustenta en las estructuras comarcales anteriores que ahora ven reforzado enormemente su papel.

La originalidad de la propuesta de organización es relativa. Cataluña, por ejemplo, según las aportaciones que realiza Cáceres (1996), pone en marcha desde 1990 lo que denominan Planes Comarcales de Montaña, con dos funciones básicas: coordinar todas las actividades e iniciativas públicas y tener una misión económica y social del desarrollo. Los objetivos e incluso el funcionamiento es similar al que el Gobierno Vasco aprueba en 1998 pero el enfoque más participativo y local que quiere aportar esta última Comunidad, la tipología de proyectos ligada a las necesidades de pequeñas comunidades y la concreción más inmediata en un documento elaborado por los propios agentes comarcales y su plasmación en planes de actuación y seguimiento anual difiere de la iniciativa catalana.

La peculiaridad del ejemplo vasco, según el espíritu del decreto, es la de aplicar el enfoque Bottom up (de abajo a arriba) propio de los programas y grupos de desarrollo rural (Sanz Hernández, 2001)9 no sólo a los fondos gestionados desde las instituciones agrarias (Leader, Proder, zonas 5.B...) y cofinanciados desde Bruselas, sino también a todas las administraciones vascas que de una manera u otra influyan en el progreso y la mejora de la calidad de vida de las comunidades rurales.

6 En 1994 se constituyó el Centro Integral para la Formación y la Promoción del Medio Rural de la Comunidad Autónoma del País Vasco MENDIKOI S.A. Sociedad Pública con entidad jurídica propia dependiente del Departamento de Industria, Agricultura y Pesca del Gobierno Vasco. Corbera, (1999), resalta entre sus funciones, la de contribuir activamente a la satisfacción de las necesidades de innovación y de desarrollo integral del medio rural vasco, que transcienden el marco del programa LEADER. A partir del año 2012 la institución cambia su denominación por la de HAZI.

7 Sirva como referencia que el País Vasco junto a Madrid son las comunidades que menor cantidad de fondos reciben a través de programa Leader, algo comprensible dadas sus características. (http://www.redestatal.com/propuestas-para-el-reparto-de-los-fondosfeader-2014-2020)

8 A diferencia de otras regiones de España en las que el programa de Agricultura de Montaña no ha funcionado y han sido los Leader los que han estructurado una política de desarrollo rural (Cruz Orozco, 1996), en el País Vasco estas estructuras han ido progresivamente incorporando programas y servicios y se convierten ahora en herramienta básica en la ejecución de estos programas.

9 Es ésta la novedad principal del ejemplo vasco puesto que la aplicación de políticas Bottom up o de abajo a arriba se limita, al menos en la Comunidad Europea, a los fondos emitidos desde esta institución y preferentemente dirigidos al desarrollo rural (Sanz Hernández, 2001). 


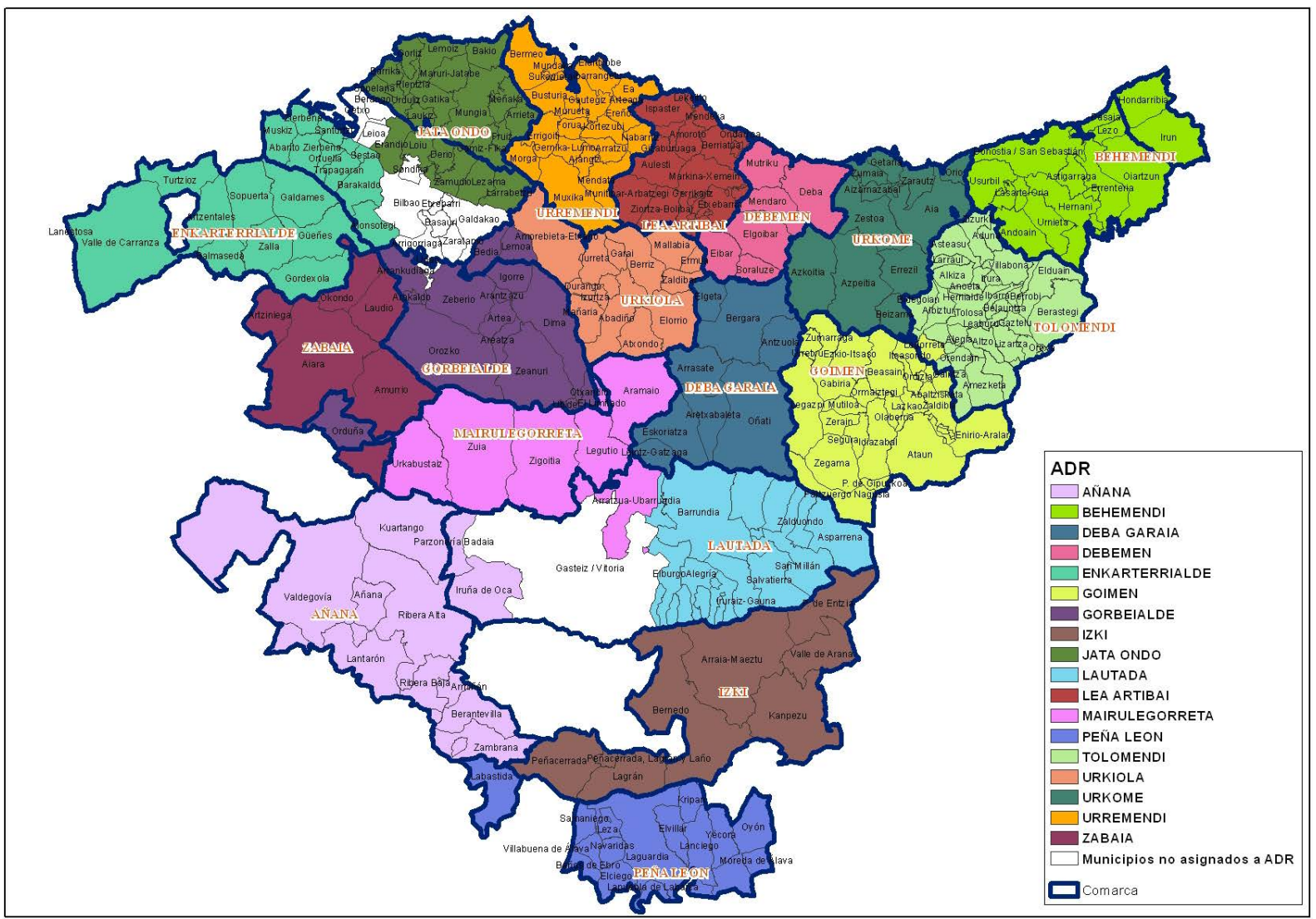

Fuente: Hazi. Programas de Desarrollo Rural del País Vasco 2015-2020 (2016).

El modelo vasco es, por tanto, un patrón con una amplia trayectoria temporal y organizativa, y podía ser un referente en el desarrollo rural en España, especialmente para aquellas comunidades que han visto mermadas las aportaciones exteriores y se ven abocadas a una reorganización de la política pública hacia el medio rural. El acierto inicial de la medida tomada queda en evidencia, entre otros aspectos, en la posterior adopción del modelo de desarrollo por otras Comunidades Autónomas, como es el caso de Navarra, en el año 2003 o por la aprobación de la Ley 45/2007 del Gobierno de España para el desarrollo sostenible del medio rural, apoyada en la colaboración interinstitucional y en el Plan de Zona como punto de partida, que provocó que muchas de las regiones españolas iniciaran su andadura (Aragón, La Rioja, Castilla- León...).

Pero ni las Comunidades que aprobaron una Ley específica ni aquellas que redactaron los Planes de Zona los pusieron en marcha. Tan sólo el Gobierno Vasco continúa aplicando el contenido legal y, como se ha señalado, de una manera muy mermada. Tras el fracaso inicial, la estructura organizativa se ha ido adecuando a la realidad de cada momento, tanto en la primera revisión del Programa que se realiza el año 2007 como en la segunda que finaliza en mayo de 2016.

Pero, qué ocurre cuando a un modelo de funcionamiento no se le permite desarrollarse del modo que estaba previsto. Lo habitual es que el modelo deje de funcionar al carecer de medios económicos y financieros, como parece que ha ocurrido en Navarra y con los Planes de Zona ${ }^{10}$.

La otra opción es la de adaptarse a las posibilidades que la nueva realidad le aporta, como acontece en el País Vasco. Si el punto de partida de la investigación parte de la consideración de un modelo de desarrollo rural integral, es decir, un patrón que plantee actuaciones en los aspectos que condicionan la

10 En las entrevistas a los coordinadores del desarrollo rural en el País Vasco se les consulta sobre el devenir de políticas similares, teniendo en cuenta que ellos participan de manera permanente en la Red Española de Desarrollo Rural (www.redr.es). Apuntan al desinterés político y a la falta de presupuesto como razonamientos que impiden la puesta en marcha de estos programas. 
actividad y calidad de vida de sus habitantes, el objeto de la misma es el de analizar cómo se ha adaptado a la nueva situación y profundizar en su funcionamiento y valía actual.

La consecución del propósito de la investigación obliga a estructurarla en la materialización de una serie de objetivos parciales. En esta investigación optamos por analizar tres aspectos diferenciados: la evolución de la metodología utilizada en la elaboración de los PDR, la variación de los contenidos de cada uno de los programas y la valoración que los agentes que intervienen en su gestión realizan de estos documentos.

La hipótesis de partida de la investigación se sustenta en la convicción de que el modelo de desarrollo resultante ha sufrido unas alteraciones tan profundas respecto a la pretensión inicial que, a pesar de que dos décadas después aún se encuentre operativo, poco o nada tiene que ver con el inicial. Es más, sin una apuesta propia por el desarrollo rural es de esperar que la iniciativa no presente diferencias significativas con las desarrolladas en otras regiones. Es decir, es de esperar que nos encontremos ante un fenómeno claro de vulgarización del modelo ${ }^{11}$.

La afirmación realizada es de suponer que vaya haciéndose cada vez más evidente en cada uno de los objetivos secundarios de la investigación. En este sentido, respecto a la evolución de la metodología utilizada, si se emplean calificativos como participativos, abiertos y ambiciosos para distinguir la elaboración de los primeros planes, es de esperar que la metodología empleada en las dos revisiones posteriores sea más somera, realista y previsiblemente menos participativa. La bibliografía consultada apunta en esta línea, como una consecuencia de la propia evolución de los programas de desarrollo rural europeos que, como señalan Wojan y Rupasingha (2001), tienden cada vez más a poner en marcha metodologías prácticas fundamentadas en la experiencia adquirida durante años

La segunda gran cuestión a abordar es la evolución de los contenidos. Si las herramientas de intervención han sido reducidas es de suponer que los retos del medio rural vasco estén aún sin afrontar o hayan quedado a expensas de su evolución temporal. Las demandas de la población rural previsiblemente no variarán desde la puesta en marcha de estos programas. De hecho, aunque las líneas de financiación tengan objetivos diferentes los programas de desarrollo rural continúan manteniendo los mismos objetivos iniciales (Nogués, 2004; Plaza, 2005) y son habituales las demandas de una población que prioriza reclamas dotacionales y de calidad de vida por encima de las propiamente económicas (Reinoso y Sancho, 2002).

Un último aspecto a investigar es afrontar la viabilidad actual de la iniciativa de desarrollo rural del País Vasco. El documento aprobado hace dos décadas es considerado por agentes e investigadores como un modelo adecuado para el País Vasco y para Comunidades con características similares (Wellbrock, et al., 2013). Al perder parte de su capacidad de acción es previsible que apenas difiera del desarrollado en otras Comunidades que, al igual que el País Vasco, tan solo cuentan con el programa Leader y la línea de mejora de calidad de vida (Nagore, 2007; Pascual, 2015). De confirmarse este extremo, la pretensión de aplicar una política Bottom up quedaría en entredicho y los PDR vascos no serían sino programas dirigidos y controlados desde una administración (Marquardt, Möllers \& Buchenrieder, 2012), con lo que otro de los pilares en los que se sustenta la Ley de Desarrollo Rural tampoco se cumpliría en este caso.

Apoyándonos en el cuestionamiento de la guía utilizada, la investigación tiene por objeto proponer un modelo de actuación que permita superar las deficiencias a las que se enfrenta el implantado en el País Vasco y que sirva de referente para otras regiones, especialmente españolas, que se encuentran ante una perspectiva similar.

\section{MÉTODO}

La obtención de los objetivos lleva a implementar un método de investigación sustentado en la puesta en marcha de diferentes prácticas para responder a los interrogantes que plantea la investigación.

11 Como consecuencia de las propuestas de evaluación de los programas de desarrollo rural que se están sucediendo en toda Europa cada vez son más las investigaciones que proponen aplicar unos procedimientos más directos, completos y, sobre todo, que busque la implicación del conjunto de administraciones. Buen ejemplo de ello son las políticas de evaluación de proyectos de desarrollo rural aplicadas en el Reino Unido y recogidas bajo la denominada "Metodología de Cardiff" (Bristow, Cowwell \& Marsden, 2001). Sin embargo, son escasos los ejemplos materializados, como señalan Wellbrock, et al., (2013) en las recomendaciones efectuadas recientemente para el conjunto de las regiones europeas. 
El recurso al análisis de artículos y trabajos científicos publicados que examinen la gestación de iniciativas similares es asignatura obligatoria para establecer el marco de referencia en el que situamos la investigación. También lo es para extraer aquellas peculiaridades que caracterizan al modelo del País Vasco y que deben ser el referente para otras áreas que se planteen la creación de acciones similares.

La escasez de publicaciones que analicen el desarrollo de diferentes programas comarcales obliga al investigador a utilizar otro tipo de fuentes, especialmente información recogida en la red por las propias ADR, informes e incluso presentaciones realizadas por los gestores del desarrollo rural en el País Vasco. Es material interno, elaborado por y para el órgano gestor de la iniciativa, entre los que resultan especialmente válidas las actas de reuniones de los diferentes agentes de desarrollo rural. En estas actas se recoge la propuesta que Mendikoi y Hazi realizan a cada una de las comarcas sobre cómo han de dirigir la elaboración de los PDR y cuáles son los elementos que han de priorizar (participación, agentes a entrevistar, información estadística...) $)^{12}$.

Otra de las fuentes priorizadas son los planes comarcales iniciales y las dos revisiones efectuadas. Estos últimos documentos son claves en el transcurso de esta investigación. Son tres los documentos elaborados por cada una de las 18 comarcas que estructuran este territorio durante las últimas dos décadas y el análisis comparativo de la metodología y los contenidos de unos y otros reflejan los elementos que han sido priorizados en cada lugar y en cada momento. En el renovado el año 2007, además, las ADR realizaron una puesta en común que resumía las prioridades por territorio, información que se incorpora a la investigación.

Pero estas fuentes requieren ser complementados con la información aportada por otros métodos. En esta investigación apostamos por la entrevista en profundidad como técnica capaz de ofrecer el contraste cualitativo a los resultados obtenidos mediante otras fuentes, y facilitar su posterior comprensión.

Dentro de las variaciones de la entrevista cualitativa, optamos por la entrevista estandarizada no programada, que se caracteriza por la utilización de cuatro criterios entrelazados: no estar excesivamente dirigida y tratar que la mayoría de las respuestas sean espontáneas en vez de forzadas o inducidas, animar al entrevistado a dar respuestas concretas, indagar en la gama de evocaciones experimentadas por el sujeto y procurar sacar las implicaciones afectivas y con carga valórica de las respuestas de los sujetos ${ }^{13}$.

Dos aspectos son relevantes en la preparación de las entrevistas en profundidad de esta investigación. En primer lugar, la planificación del guión de la entrevista, que contiene los temas que deben cubrirse, a partir de los objetivos de la investigación. Elegimos un esquema abierto, con puntos a tratar, cuyo orden no tiene que seguirse necesariamente, que recoge el flujo particular de información del entrevistado y que capta aspectos no previstos en el guion. De este modo, se crea una relación dinámica en la que se van generando los temas de acuerdo al entrevistado, sin regirse a un orden prefijado.

En segundo lugar, la selección de entrevistados. Planificamos las conversaciones en dos niveles, diferentes pero complementarios entre sí:

El informador relevante. Diálogos con tres representantes de Hazi, responsable del funcionamiento de la política de desarrollo rural en el País Vasco. Ellos poseen una visión general sobre el funcionamiento de los programas de desarrollo rural en el País Vasco, la implicación de las diferentes instituciones e incluso la inserción de estos programas en el marco comunitario. Colaboran habitualmente en la dirección de la Red de Desarrollo Rural de España, lo que les aporta un conocimiento global sobre las peculiaridades y posibilidades del modelo de desarrollo vasco

El informador representativo, aquel que participa en la iniciativa y que da información sobre su funcionamiento desde una óptica local. Entrevistamos diez de los dieciocho gerentes de las ADR del País Vasco. Se les cuestiona sobre el grado de cumplimiento de los objetivos del PDR del 2007, de cada uno de sus ejes, y se les interroga sobre las expectativas que el nuevo PDR, aprobado el año 2016, representa para ellos.

12 El investigador colabora con los dinamizadores de los programas de desarrollo rural desde su inicio, lo que le permite participar en los debates y tener acceso a las actas de los mismos. Asimismo, los diferentes planes de desarrollo rural del País Vasco se pueden consultar en el web: www.nasdap.ejgv.euskadi.eus/informacion/programas-de-desarrollo-rural-comarcales-2015-2020/r50-5333/es/. Los planes relativos del año 1998 y el 2007 no se encuentran a disposición de usuario pero el investigador cuenta con una copia que pone a disposición de las personas interesadas, al igual que las actas de las reuniones que tanto Mendikoi como Hazi han ido confeccionando a lo largo de estas décadas.

13 Las diferentes tipologías de entrevistas cualificadas son ampliamente estudiadas por Guerrero (2014). Dentro de la categoría señalada agrega una subcategoría que también incorporamos en el estudio, la entrevista especializada y a elites, en la cual se enfatiza la definición de la situación del entrevistado, animándolo a estructurar el relato de la situación y a incorporar sus nociones de lo que considera relevante. 
La colaboración habitual del investigador en diferentes proyectos e exploraciones con los agentes de desarrollo rural del País Vasco facilita el conocimiento del campo de análisis y le allana el acceso al informador, permitiéndole profundizar en una relación de confianza en aspectos trascendentales para la investigación ${ }^{14}$.

\section{RESULTADOS}

La falta de colaboración interadministrativa provoca que los principios recogidos en la Ley de Desarrollo Rural no se materialicen. Sin embargo, la Ley sigue vigente hoy en día y las entidades de desarrollo rural continúan realizando su labor diaria. En este apartado profundizamos en el progreso que ha tenido el desarrollo rural en el País Vasco desde que quedarán en evidencia las deficiencias de la guía. Los cambios se afirman en el modo de actuar, en los contenidos de los planes y en la valoración de los agentes responsables del desarrollo rural.

\subsection{Del diagnóstico a los grupos de trabajo, evolución del método de intervención}

Las dificultades de materialización de la Ley de Desarrollo Rural no eximen de su cumplimiento y los programas, como se recoge en el decreto, han de renovándose periódicamente. Aparentemente, el esquema metodológico de los nuevos PDR no cambia respecto a la fase inicial. La estructuración es similar, coincidiendo con la utilizada habitualmente en la redacción de planes de desarrollo y que se concreta en una primera fase de organización del proceso, un diagnóstico, formulación de la estrategia, planificación para finalizar en una última fase de despliegue, seguimiento y actualización.

Una vez examinados los planteamientos realizados en cada uno de los apartados desde la primera revisión (2007) ya se observa una evolución importante respecto a la metodología del programa de 1998 e incluso a la utilizada habitualmente en la redacción de planes de desarrollo, de la que destacamos los siguientes aspectos:

- En la organización del proceso se establece un responsable máximo, el gerente de la ADR correspondiente. El gerente ha de consultar a la junta de la ADR, ha de cumplir las directrices marcadas por la entidad coordinadora de los programas (Mendikoi) pero asume ahora la responsabilidad de que la organización sea correcta, el diagnóstico adecuado, se formulen las estrategias ajustadas y se planifique su materialización y seguimiento ${ }^{15}$.

- El modo de participación cambia sustancialmente. De apostar por un modelo abierto, apoyado en diferentes grupos de trabajo y en dinámicas de encuentros sectoriales y comarcales, se prima la participación selectiva, dirigida por un objetivo, sustentada en la entrevista y promovida por la gerencia de la ADR. Apenas se utilizan datos estadísticos y se opta por tomar como referente la opinión que, en función de los objetivos planteados, han ido aportando las diferentes personas entrevistadas. Con ello consiguen un documento abarcable y manejable, frente al carácter de volumen que tenía el anterior ${ }^{16}$.

La organización propuesta condiciona el carácter del proyecto. La Formulación de la Estrategia adquiere un peso fundamental. El objetivo de esta fase es el de obtener una visión de futuro para el medio rural de la comarca, compartida por los diversos agentes que operan en ella, e identificar los principales ejes en los que sustentar la estrategia de desarrollo del medio rural comarcal, que van a permitir el logro de la visión en el tiempo. Ello supone en primer lugar marcarse un horizonte a medio-largo plazo sobre el medio rural que pretenden alcanzar y, posteriormente, identificar los cuatro o cinco ejes de desarrollo prioritarios para la comarca. Esta es una labor a realizar por la ADR, contrastada con la visión de una serie

14 El recurso a la segunda entrevista en busca de una relación de confianza con el informador es una metodología utilizada habitualmente en los estudios etnográficos, sociales y rurales (Guber, 2001)

15 La figura del gerente se asimila en cierta medida a la del facilitador, entendido como aquella persona que estimula la acción colectiva a través de la adquisición de habilidades y actitudes personales desempeñadas en un grupo de trabajo. Además de la realización de una tarea común, la facilitación pretende crear relaciones y vínculos de confianza en el grupo, que permitan a sus componentes actuar conjuntamente en la resolución de problemas (Viduera, Fernández y Gallego, 2013).

16 Las posibilidades de éxito de esta fase estriban en tener la habilidad de crear un esquema de trabajo que pase de la planificación compartida a la acción compartida, para lo que se hace obligatorio concertar actuaciones con agentes claves. En definitiva, como señala Viñas (2004), se trata de poner en marcha un enfoque cualitativo fundamentado en una reflexión previa y que ayude a decidir en cada caso la combinación metodológica más adecuada. 
de agentes clave, y que pretende romper con el listado inabarcable de estrategias y subestrategias que se recogían en la fase anterior ${ }^{17}$.

La última revisión realizada el año 2016 ahonda en los cambios que en el periodo anterior ya se habían establecido (ver tabla 1). Como punto de partida desde la dirección de la ADR proceden a la evaluación de los Programas de Desarrollo Rural anteriores (2007-2013), pero desde una visión crítica, analizando la información sobre el grado de desarrollo de sus estrategias, argumentando el porqué de sus éxitos y fracasos y la evolución de los indicadores socioeconómicos globales a lo largo del periodo.

El avance prioritario se establece en el contenido del programa de desarrollo rural. El diagnóstico se concreta exclusivamente en una revisión de la DAFO del periodo anterior por parte del equipo gestor, en la que han considerado la vigencia de cada uno de los factores, su prioridad, nuevos ítems a incluir... Se subraya lo que denominan valor diferencial, es decir, factores positivos clave que diferencian a la comarca del resto, y las barreras para el desarrollo o los factores negativos clave que dificultan el desarrollo de las zonas rurales de la comarca. Unos y otros elementos son consecuencia de la reflexión interna del equipo gestor de la ADR y en ellos el diagnóstico queda vaciado de contenido.

Tabla 1. Esquema metodológico de la de elaboración de los PDR. 1998-2016

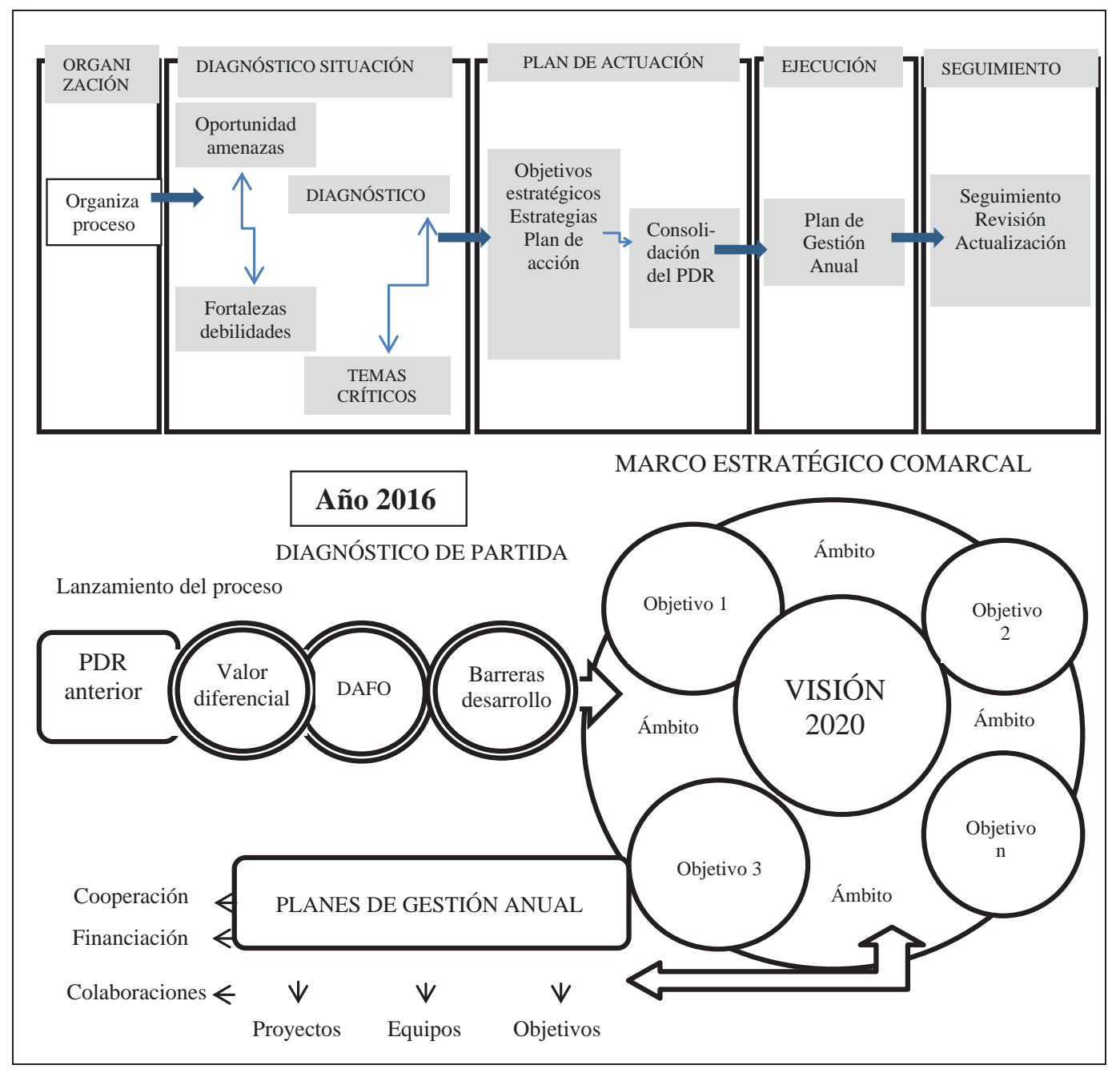

Fuente: Mendikoi (1998) y Hazi (2016). Elaboración propia.

17 Desde hace algunas décadas se ha empezado a considerar importante realizar evaluaciones participativas, es decir, evaluaciones en las que los beneficiarios no sean meramente fuente de datos, sino que participen también en el diseño, realización y análisis de los datos de la evaluación. Esto se ha conseguido en diversos grados, pero al menos se ha extendido la idea de que tales intentos darán más calidad a las evaluaciones y permitirán a los evaluadores sacar conclusiones más pertinentes (Casley y Kumar, 1990; Murray, 2002; Patton, 2002; Andrés, 2010; Oliva e Iso, 2014). 
Los esfuerzos se centran en formular el marco estratégico comarcal. Este marco es el que recoge la estrategia de desarrollo a medio plazo (2015-2020) de las zonas rurales de la comarca; es decir, hacia donde quieren ir, que camino han de recorrer y cómo han de hacerlo, concretándose en los pasos que ya se definían en la fase anterior (visión de futuro, ámbitos estratégicos y objetivos). A diferencia del periodo anterior, en vez de apoyarse en la entrevista, reúnen a los miembros de la red de agentes comarcales y en varias sesiones conjuntas, acudiendo a metodologías participativas, definen los ámbitos estratégicos y los objetivos que ha de tener la comarca en materia de desarrollo rural. Aprueban en primer lugar los ámbitos a acometer y para cada uno de ellos definen una serie de objetivos concretos (ver tabla 2)

El objetivo de reforzar la intervención de agentes comarcales en el PDR estriba en el nuevo planteamiento de despliegue del mismo, concretado en la convocatoria periódica de varias mesas de trabajo en cada comarca para abordar los ejes prioritarios que se han considerado anualmente y en la realización de una planificación anual, indispensable ahora para que un proyecto pueda ser financiado por las entidades públicas.

La metodología presentada responde a los objetivos que se había propuesto, primando la sencillez y agilidad, el carácter dirigido y la pretensión realista que se le quiere dar, apostando por la obtención de unos objetivos abarcables con la actividad de las Asociaciones. La peculiaridad estriba en la necesidad de implicar a agentes locales que puedan aportar ideas y recursos para el desarrollo comarcal y hacerlo de una manera más o menos permanente.

El modelo de actuación presentado responde a la evolución propia de un programa de desarrollo rural que se fundamenta cada vez más en la práctica que año tras año va adquiriendo y que queda en evidencia una vez que se realiza un ejercicio de valoración de sus resultados.

\subsection{Diagnóstico, ejes y objetivos se repiten programa a programa}

En el PDR 2007-13, la identificación de temas críticos comunes a todas las comarcas constituye una tarea cuyos promotores (Mendikoi y ADR) consideran que aporta valor añadido al programa. Responde todavía a la idea original de la Ley de Desarrollo Rural, en la que este proceso debía ser la base de posibles estrategias de "reconversión" que requieran el concurso de administraciones supracomarcales con competencias en distintos. En sí, es es un ejercicio que reúne las demandas y oportunidades de desarrollo propuestas por las diferentes áreas rurales del País Vasco cuyas conclusiones sintetizamos a continuación ${ }^{18}$ :

- Turismo. Llegan a la conclusión de que las zonas rurales poseen una riqueza paisajística y natural, y un patrimonio cultural, arquitectónico e histórico de alto valor, junto a una amplia oferta de ocio natural, cultural, de playa y gastronómica. Y esto se realiza cerca de un entorno urbano receptor de turismo en la proximidad, al que ofertar nuevos productos turísticos. En cuanto a la estructuración del turismo en las diferentes comarcas concluyen que los factores, en general debilidades, se repiten. Destacan la falta de una visión para abordar su desarrollo y en consecuencia la gestión del progreso del turismo se encuentra poco organizada, no se planifica ni se define el modelo a impulsar y la coordinación entre las administraciones competentes y el sector privado es escasa.

- Demografía, cultura y cohesión comarcal. Población envejecida, con comarcas donde comienzan a detectarse problemas de integración y de identidad, que deriva en una merma de la vida social del municipio. Asimismo apuntan falta de visión comarcal y escasa coordinación entre las entidades y organismos que trabajan en el desarrollo socio económico de la comarcas ${ }^{19}$.

- Economía rural y calidad de vida. Se anota una deficiente oferta en servicios, equipamientos e infraestructuras, ausencia de centros escolares, falta de especialidades en los centros sanitarios, falta de ambulancia medicalizada y limitaciones del transporte público ${ }^{20}$. Por otro, señalan el escaso dinamismo

18 Los contenidos de los Planes Comarcales elaborados el año 2007 son recogidos en una publicación en la que se profundiza en las peculiaridades comarcales, provinciales e incluso regionales. Consultar Alberdi, 2010.

19 La soledad en los espacios rurales, como señalan García y Rodríguez (2004), se manifiesta en un vacío cultural, en una progresiva pérdida de valores y de identidad, falta de comunicación o en un excesivo tiempo libre. Para evitarlas se ha de impulsar la inserción social, la solidaridad y ayuda mutua, la comunicación y la convivencia. Andrés (2010), profundizando en la idea, apunta a la necesidad de renovar, de reinventarse, de superar la autocomplacencia, sin olvidar el origen y la tradición rural de la comunidad.

20 Responde a la cada vez mayor demanda de la población que vive de forma continuada en el medio rural y que está condicionada por el envejecimiento generalizado de sus habitantes. Es una demanda común de las zonas rurales. Reinoso y Sancho (2002) apuntan a los servicios públicos como los más demandados en la Sierra Norte de Guadalajara, especialmente a la mejora de la asistencia sanitaria y en segundo lugar al incremento del transporte público. 
empresarial y falta de actividad económica de algunas comarcas. Como grandes oportunidades del medio rural vislumbran las posibilidades del desarrollo de nuevos yacimientos de empleo relacionados con la gestión del medio natural, debido a la constatada demanda creciente hacia el uso de espacios naturales para el ocio y tiempo libre.

- Sector primario. El declive en el sector primario es un hecho que se constata en todas las comarcas, con temas comunes que en todas ellas se repiten como la falta de relevo generacional, la baja rentabilidad de las explotaciones.... Se apuntan como grandes oportunidades la proximidad de la producción a los potenciales consumidores de productos agroalimentarios, la existencia de un gran número de ferias, el aumento de la demanda de productos de calidad y los circuitos cortos de comercialización.

Los ejes en los que se estructura deja entrever cuales son los aspectos que preocupan a las diferentes Asociaciones de Desarrollo Rural. Agricultura, Calidad de Vida, Diversificación Económica y Turismo, y Cohesión Territorial e Identidad son los que estructuran la fase de planificación de los Planes de Desarrollo, aspectos todos ellos que ya quedaban patentes desde la fase de diagnóstico ${ }^{21}$. El PDR del periodo 2015-2020 reproduce en términos generales los ejes, objetivos y buena parte de las estrategias que ya se recogían en el anterior, salvo la ausencia de un documento global. Por lo demás los documentos, salvando las peculiaridades de cada lugar, se concretan mayoritariamente en tres ejes prioritarios, el desarrollo de la agricultura, la promoción del tejido económico local y la mejora de la calidad de vida rural (ver tabla 2) ${ }^{22}$.

Tabla 2. Ámbitos y objetivos que estructuran el PDR de Añana en Álava. 2016

Ámbito $\mathrm{n}^{\mathrm{o}}$ 1. Sector primario y agroalimentario diversificado y con valor añadido

$\square$ Favorecer las nuevas incorporaciones y rejuvecer el sector
$\square$ Diversificar el sector impulsando nuevos productos y su transformación
$\square$ Facilitar la formación y capacitación
$\square$ Mejorar la imagen del sector a traves de la sensibilización interna y social
$\square$ Desarrollar servicios e infraestructuras colectivas
$\square$ Facilitare el acceso a tierras y sistemas de transmisión
$\square$ Aumentar el número de operadores en ecológico
$\square$ Mejorar la competitividad y sostenibilidad del sector
$\square$ Coordinar y cooperara con los diferentes agentes sectoriales a nivel comarcal

Ámbito $\mathrm{n}^{\circ}$ 2. Desarrollo económico sostenible: turismo de naturaleza y patrimonial como motor de una amplia red de actividades económicas, emprendimiento y desarrollo industrial

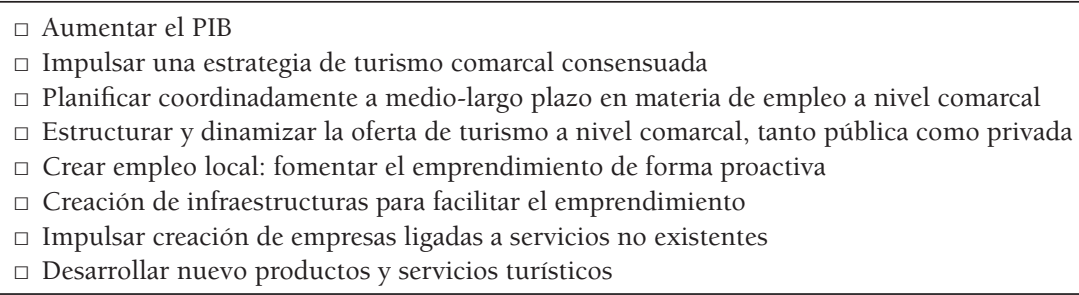

Ámbito n 3. Acceso a servicios de calidad para la población (identidad, equilibrio, oferta de servicios...)

$\square$ Coordinación y colaboración entre entidades locales para la prestación de servicios

$\square$ Garantizar la atención a las necesidades de la población mayor, jóven y mujeres especialmente

$\square$ Garantizar el acceso a las TICS y la oferta de servicios a toda la población de la comarca

$\square$ Fomentar actividades que refuerzen la identidad y coordinación comarcal (ferias, eventos deportivos....)

$\square$ Crear foros periódicos con las administraciones y entidades locales

$\square$ Favorecer un desarrollo comarcal en equilibrio con el medio natural: poner en valor red natura....

Fuente: www.valdegobia.org. Elaboración propia

21 Objetivos compartidos en la mayoría de los programas de desarrollo rural. Como señala Plaza (2005), para el logro de sus objetivos Proder adoptó una estructura práctica articulada en torno a diversas medidas y acciones, siguiendo, de este modo, un modelo de aplicación muy similar a la iniciativa Leader, si bien una de las diferencias entre ambos es que en Proder no se contemplaba la cooperación transnacional que sí existía en Leader. Las medidas del Programa Operativo de Desarrollo y Diversificación Económica de las Zonas Rurales Objetivo 1 de España aparecidas en la Resolución del 3 de Febrero de 1997 se agruparon en torno a los siguientes ejes financiados, cada uno, por uno u otro de los fondos estructurales comunitarios que se señalan. El patrimonio, el turismo, las empresas y las propias actividades y potenciales agroforestales se convirtieron en los vértices de referencia de aplicación del programa.

22 Todos los PDR reflejan esta división pero un buen ejemplo sobre el proceso y la discusión planteada se recoge la Comarca de Añana (Álava), una muestra de cuáles son sus ejes y sus objetivos. http://www.valdegovia.org/fotos/PDR\%20Valles\%20Alaveses\%2014\%20 de\%20diciembre\%202015.pdf 
El diagnóstico de cada territorio muestra una visión común sobre la situación y demandas de los espacios rurales. Entre las preocupaciones vuelve a subrayarse la crisis de la agricultura. Apenas hay agricultores, no hay continuidad, las condiciones de trabajo son malas y las posibilidades de atracción de nuevo personal muy reducidas. Inquieta también las deficiencias que se producen en la dotación de servicios básicos: Los pueblos rurales carecen de muchos de los servicios por una normativa que no se adapta a la realidad de estos espacios. Un último aspecto a destacar es la falta de visión de comarca, lo que dificulta el trabajo en pos de un objetivo común, junto a la casi inexistente relación entre comarcas, territorios y administraciones.

Los puntos fuertes también son comunes, de los que destacamos dos, básicos a la hora de realizar planteamientos de futuro. En primer lugar, el reconocimiento de la calidad y valoración del medio en el que habitan por el conjunto de la sociedad, como característica capaz de generar riqueza económica (turismo, actividades de la naturaleza, recreo, gastronomía,...) En segundo lugar, la relativa proximidad de una gran zona urbana, aspecto que se produce en la mayoría de las comarcas y que contribuye a aportar empleo e incluso atraer actividades urbanas al medio rural

Al igual que el diagnóstico, la visión es en gran medida compartida. En todos los casos se busca defender un entorno rural vivo y con identidad propia. El futuro pasa por mantener la actividad económica que le ha aportado su carácter actual, la agricultura, una actividad que ha de obtener mayor valor añadido y que ha de diversificarse. Por otro lado, se aspira a conseguir un medio rural en el que la calidad de vida de su habitante ha de estar, al menos en cuanto a la dotación de servicios básicos, garantizada. En definitiva, un medio rural sostenible y apoyado en un desarrollo endógeno.

Las inquietudes son análogas, aunque difieren algunos objetivos y líneas estratégicas. La preocupación por la situación del sector agrario es similar, se comparten las propuestas relativas a la mejora de servicios en el medio rural, la necesidad de reconocimiento por parte de la administración de las aportaciones de este espacio, la falta de coordinación y la necesidad de movilizar al habitante rural en pos del desarrollo de su barrio o pueblo.

Las diferencias principales se establecen en función del grado de proximidad al medio urbano. En algunos casos preocupa la excesiva cercanía, la especulación que provoca sobre el suelo o la construcción de nueva vivienda, con un recién llegado que ni se integra ni le interesa la dinámica social del lugar en el que habita. En otros, interesa convertir el territorio en un espacio atractivo para las inversiones urbanas, desde llegada de población hasta, y sobre todo, atracción de actividades económicas motoras.

Como podemos observar la aplicación metodológica no varía los resultados obtenidos, similares a los señalados una y dos décadas antes en los Planes de desarrollo rural (Alberdi, 2004) y que, salvo la particularidad de la proximidad urbana, apenas difieren de las demandas habituales de otras zonas rurales (Reinoso y Sancho en la serranía de Guadalajara, 2002; Cejudo y Navarro en Granada, 2003; Alario y Baraja en Castilla-León, 2006;... ). Lo que la nueva metodología aporta es simplicidad y puesta en común pero las demandas y soluciones propuestas siguen siendo las habituales.

Pero el nuevo documento marca nuevos pasos en pos de la consecución de una mayor operatividad. El principal es la decisión de no elaborar una estrategia referente para otras administraciones que deberían implicarse en materia de desarrollo rural. Se produce ya una dejación efectiva de la que se consideraba la principal aportación de la Ley de Desarrollo Rural.

La renuncia a la intervención de otras administraciones y departamentos diferentes al sectorial (Agricultura y Desarrollo Rural) condiciona el periodo de aplicación del programa de desarrollo. Se hace coincidir la programación del PDR con la aprobación del Plan de desarrollo Rural Sostenible del País Vasco (2014-2020) por parte de la Comunidad Europea puesto que será el programa Leader, cofinanciado por Europa, la vía de financiación priorizada, junto al eje IX relativo a la mejora de la calidad de vida del PDRs.

\subsection{Entre la resignación y la necesidad de proseguir}

Las entrevistas, todas ellas conversiones individuales abiertas, son orientadas según las características de cada uno de los grupos con los que se plática. Con el primer grupo, los gerentes de las ADR, conversamos sobre los resultados obtenidos la última década, valoramos la utilidad de los PDR como herramienta de desarrollo y les interrogamos sobre las perspectivas que el nuevo documento les ofrece. 
De las entrevistas obtenemos una valoración global. Consideran al PDR una herramienta interna, que nadie consulta y que carece de eficacia. Señalan las mismas críticas que caracterizaron al documento inicial: falta de apoyo político, económico, ignorancia del marco legal, desinterés..., a los que se le unen ahora calificativos dirigidos a la administración de desarrollo rural: excesiva direccionalidad, falta de dejación de la capacidad de decisión... ${ }^{23}$ Su despliegue, fundamentados en la elaboración de Planes Anuales, es considerado infructuoso ${ }^{24}$.

Desgranando los resultados en función del grado de consecución de cada uno de los ejes en los que el Programa había sido distribuido, los agentes entrevistados resaltan las siguientes conclusiones.

- En materia de turismo subrayan un acercamiento de las instituciones al mundo agrario, especialmente a sus productos, motivado por el interés de promocionar la gastronomía vasca. Pero los errores apuntados en la redacción del documento (falta de coordinación, inexistencia de un proyecto, falta de estrategia...) no se han corregido y ahora se les añade la excesiva direccionalidad marcada por un programa (turismo gastronómico), dirigido por el Departamento de Turismo, administración que desconoce el PDR y no cuenta con las ADR.

- El declive del sector primario ha sido mayor que el esperado. Éste era y sigue siendo el área de actuación priorizada pero las asociaciones carecen de instrumentos para actuar y las políticas de la administración son insuficientes. Cumplen la función de meros espectadores ante la desaparición del sector que consideran estratégico para el medio rural.

- En los ámbitos relacionados con la calidad de vida y la cohesión social son muchas las comarcas que no han realizado o promovido acciones, justificándose en la falta de apoyo presupuestario para ejecutarlas. Las que han actuado han dirigido sus operaciones a la urbanización y embellecimiento de núcleos rurales, beneficiarios principales del eje IX del PDRs. Los objetivos que perseguían promover el sentimiento de pertenencia, la participación local... continúan pendientes y la pérdida de población es ya un problema acuciante en las comarcas más alejadas de las zonas urbanas.

- La economía local se ha concretado en el apoyo a Pymes en zonas rurales. Promovido por único grupo Leader existente, que aglutina a todas las ADR del País Vasco, ha sido clave en el apoyo económico a la creación e inversión de la empresa local. Los resultados obtenidos, prioritarios para aquellas zonas más alejadas de los núcleos urbanos, son valorados positivamente, especialmente en los casos en los que se beneficiaba a la iniciativa local, aunque continúan resaltando la falta de emprendedores ${ }^{25}$.

Las entrevistas realizadas coinciden con la finalización y presentación del Programa 2015-2020. Ello permite valorar las expectativas puestas en la elaboración del nuevo documento. Queda escenificada la duda extendida respecto a la efectividad del nuevo PDR. Algunas afirmaciones tachan al documento de trámite impuesto, de continuidad del anterior con otro lenguaje. Otras resaltan la falta de ayuda suficiente, la escasa participación de otras administraciones, el hastío entre los agentes locales y, aunque también se señalan comentarios positivos, en todas las entrevistas queda patente el recelo que la iniciativa genera.

Pero la colaboración en materia de desarrollo rural también evoluciona, se adapta y busca nuevas vías. Varios de los entrevistados apuntan al funcionamiento mediante grupos de trabajo como adecuado para conseguir una mayor implicación de personas e instituciones, especialmente de las locales. Son varias las Asociaciones que convocan una mesa de alcaldes como medio de discusión, de presión y de financiación de proyectos. Asimismo la organización de grupos de trabajo refuerza la capacidad que cada ADR tiene

23 Son calificativos que ya se señalan en otras investigaciones que analizan la actuación de los Grupos de Acción Local (Esparcia y Noguera, 2000; Navarro, Cejudo y Maroto, 2014) apuntando como habitual que la administración ha sido reticente a compartir el poder. Incluso, en gran parte de las ocasiones, los Grupos de Acción Local no decidían sobre los proyectos y fondos, lo que provocaba que los PDR fueran entendidos como programas externos y no como instrumentos del desarrollo endógeno.

24 Apuntan también la batería de indicadores que se pretendía poner a cada acción propuesta, algo que aún complicaba más la elaboración y seguimiento del Plan, con unos resultados que nunca fueron evaluados, unas exigencias impuestas desde la Comisión Europea que como señalan Sancho y Reinoso (2013) plantea conocer la incidencia de los mismos en los territorios a medio y largo plazo en un intento de abrir el horizonte y preguntarse por los objetivos globales, de calado más profundo, que siempre deben animar cualquier acción territorial. Estos objetivos, al menos en el ejemplo vasco, no han sido conseguidos.

25 En este mismo sentido se pronuncian otros estudiosos de las iniciativas de desarrollo rural. Cejudo y Navarro, (2009) a través del ejemplo de Granada ya apuntan que la ausencia de emprendedores privados ni ha sido cubierta, ni puede serlo, de forma permanente por las instituciones públicas. Se requiere la necesidad imperiosa de que los Grupos retomen su labor dinamizadora, obligadamente arrinconada, de periodos anteriores. Buscar, formar, cualificar emprendedores autóctonos o alóctonos para la puesta en marcha de proyectos en estos espacios deprimidos en base a altos niveles de financiación pública procedentes de estos programas o de otro tipo de incentivos que se pudieran desarrollar es urgente e imprescindible. 
para generar dinámicas locales, aglutinando a agentes con facultad de opinión e intervención, y que pueden ser fácilmente movilizados en otros proyectos que tengan a la comarca y al medio rural como referente.

El compromiso del Departamento de Desarrollo Rural del Gobierno Vasco de ligar a la redacción del Plan Anual de cada ADR la posible financiación de iniciativas comarcales en sus programas de desarrollo rural da importancia a esta metodología, suscitando un interés del que carecía antes.

La entrevista individualizada a tres miembros de Hazi, coordinadores de los programas de desarrollo rural en el País Vasco, completa la visión aportada por los gerentes. Se les interroga sobre cuestiones más generales, relacionadas con el funcionamiento de la política de desarrollo rural, lo que permite obtener una visión más completa sobre la capacidad real y perspectivas de estos programas en el País Vasco. Las aportaciones son amplias, y procedemos a agruparlas en cuatro ámbitos diferenciados:

- Las demandas de las ADR recogidas en los programas de desarrollo rural no han variado desde 1998. La metodología ha cambiado, incluso las líneas de financiación se han ido adecuado a nuevas realidades, pero los contenidos del diagnóstico, la visión y los ejes de actuación propuestos son similares.

- Convencimiento de la validez de la Ley de Desarrollo Rural y del modelo de organización que emana de ella, a pesar de la falta de colaboración con otras administraciones. Para ellos sigue siendo un modelo fundamental puesto que se considera a la transversalidad como herramienta para garantizar el progreso de las comunidades rurales. Los PDR siguen teniendo la función de orientarles hacia donde tienen que trabajar y apuntan la necesidad de renovar la Ley, de aportarle mayor practicidad, acción que ha de venir de la mano de la dinamización de las Landas Territoriales, órganos interadministrativos que han de cumplir la función de discutir la política de desarrollo rural a instaurar en cada territorio.

- Sensación de avanzar a remolque de otras políticas, incluso entre las mismas políticas sectoriales. Los Planes de Desarrollo Rural han de ser redactados previamente a la definición del PDRs de la Comunidad Autónoma para que sus exigencias sean recogidas en este documento, que marcará el devenir del progreso rural y agrario los próximos seis años. Pero no ocurre así y el PDRs se aprueba previamente a la redacción de los Planes de Desarrollo, a los que no les queda otra opción que adecuarse a los que éstos requieren (amplias zonas rurales no se benefician de ayudas, demandas tradicionales no son recogidas, las decisiones se han tomado previamente.... $)^{26}$.

- La organización como un reto continuo. Cada nuevo programa requiere una adaptación del modelo de organización. La estrategia para el periodo 2015-20 se fundamenta en la dinamización de los grupos de trabajo y la operatividad del plan anual.

Los responsables defienden la particularidad del modelo vasco, diferenciándola de la organización habitual de las redes de desarrollo rural y los grupos Leader, entre otros aspectos, por la existencia de un marco legal concreto, por su pretensión de ejecutar una política de desarrollo integral, por su carácter local y por su materialización en todo el territorio y no exclusivamente en áreas y proyectos demostrativos específicos.

\section{DISCUSIÓN}

La política de desarrollo rural del País Vasco se vio inicialmente impulsada por los diferentes programas que desde la Unión Europea se iban poniendo en marcha en materia de desarrollo rural. Su carácter parcial (carácter demostrativo orientado a diferentes zonas de los programas Leader) y la insuficiencia de los fondos comunitarios aportados hacía necesario plantear un proceso de actuación diferente en esta región, fundamentado en una participación activa y coordinada en materia de desarrollo rural de las diferentes instituciones con las que cuenta la región y que inicia su andadura con la aprobación de la Ley de Desarrollo Rural en 1998.

\footnotetext{
26 Son muchos los investigadores que critican la supuesta autonomía de los grupos de desarrollo rural [GAL] para materializar una política apoyada en los intereses locales. Sirva como referencia la opinión de Navarro, et al. (2014) respecto a la política de estos grupos apuntando que la instrumentalización de los GAL por el poder político, social y económico ha hecho que los PDR refuercen las estructuras de poder y, al mismo tiempo, contribuyan a la exclusión de los grupos con menores posibilidades. La actual postura de la Comisión Europea hacia la participación en el desarrollo rural no es más que mera retórica. En la misma línea se expresan otras investigaciones, que apuntan la dificultad de dar inicio a una política Bottom up y al excesivo control público de la iniciativa (Gil de Arriba, 1998; Esparcia, 2014).
} 
La apuesta vasca, sin embargo, falla desde su inicio, lo que le obliga a ir adecuándose a la situación de cada momento. En general, mantiene su estructura organizativa, es decir, coordinación e implicación de la administración responsable del desarrollo rural y programas de desarrollo y asociaciones comarcales como medio de captar necesidades, plantear y ejecutar actuaciones. Sin embargo, cambia el modo de realizar los programas de desarrollo y también difiere el modo de actuar. Tras variadas décadas dedicadas a la promoción del medio rural se ha impuesto un modelo de actuación cada vez más pragmático, preocupado por no generar falsas expectativas entre la población rural y primando la gestión ágil y realista.

Sin romper con la anterior, cada nueva etapa toma lo que mejor se adecúa a las nuevas circunstancias hasta conseguir el patrón de funcionamiento actual ${ }^{27}$. Del modelo original, iniciado junto a la aprobación de la Ley de Desarrollo Rural, se mantienen actualmente al menos dos características básicas:

- La problemática y demandas rurales, que no difieren demasiado de unas zonas a otras. La metodología muestra matices locales en una realidad global, apreciaciones que en el País Vasco parecen estar relacionadas con la mayor o menor proximidad al medio urbano.

- Los objetivos son compartidos y apenas difieren de unos a otros, es decir, conseguir un medio rural vivo, independiente y diferenciado en una gran región urbana, como es el conjunto del País Vasco.

La primera revisión efectuada (periodo 2007-13) mantiene el diagnóstico e incluso los objetivos de la anterior pero rompe con el modo de actuar. En la evolución hacia el modelo actual destacamos dos aspectos relevantes:

- La metodología utilizada en la redacción de los Planes de Desarrollo Rural conserva la estructura habitual diferenciada entre el diagnóstico y el plan de actuación pero ya vaciado de contenido. No se busca la participación de todos los agentes y personas implicadas, las reuniones se reducen, los aspectos descriptivos se suprimen y el documento final pierde volumen. Sin embargo, se gana en operatividad y direccionalidad.

- Aunque inicialmente surge con otro objetivo, hacen coincidir la vigencia del PDR con la programación Europea, con el objeto de justificar las inversiones procedentes de tal institución y los fondos propios del Departamento de Desarrollo Rural, único valedor de la política de desarrollo rural.

- La implicación de los agentes que pueden intervenir en el desarrollo rural continúa siendo clave, especialmente de la administración pública, a la que los agentes le siguen solicitando una política específica para el medio rural. Por ello, a pesar del escaso éxito obtenido en este campo, consideran necesario que las reivindicaciones de las comarcas y territorios vascos sean comunes, así como las líneas de actuación.

El modelo actual (2015-2020), cuyos PDR son presentados al conjunto de la sociedad el 13 de Mayo de 2016, supone la consolidación del modelo precedente, aportando tres avances referenciales:

- Se asienta definitivamente una metodología en el que priman los ámbitos y objetivos de la estrategia y se arrincona la necesidad de hacer un diagnóstico de la situación del medio rural de la Comarca, con un modelo que apuesta por la consulta selectiva frente a la participación ciudadana.

- La operatividad de los Planes se fundamenta en la participación periódica de agentes en mesas de trabajo y en la consecuente realización del Plan Anual, documento referente a la hora de financiar las propuestas apuntadas.

- Renuncia implícita a presentar propuestas territoriales dirigidas a departamentos e instituciones diferentes a las de desarrollo rural.

La mutación del modelo de desarrollo rural expuesta es consecuencia de la falta de compromiso de las administraciones no agrarias para abordar una política específica para las zonas rurales, más allá de la que hasta ese momento ya tenían en marcha. Esta falta de implicación invalida la oportunidad del modo de actuación propuesto originalmente puesto que éste queda vaciado de contenido.

27 Parece una constante en los programas de desarrollo rural la necesidad de ir adecuándose a una realidad cambiante que necesita de todos los agentes, tanto públicos como privados. Al menos es a la conclusión a la que llegan Wellbrock, et al. (2013), en un análisis sobre los proyectos de partenariado rural en Europa apuntado que elevar una agencia colectiva eficaz requiere una reconsideración conjunta y la reestructuración de la división de funciones y tareas, incluidas las de la administración pública. Esto puede ser apoyado con reflexividad conjunta entre los actores del desarrollo y dar espacio para el liderazgo colaborativo y la flexibilidad operativa con el apoyo político. 
El campo de actuación que el modelo de desarrollo rural tiene es limitado. Son dos los programas impulsados, Leader y Erein (eje IX del PDRs) ${ }^{28}$. El primero se centra en el apoyo a la creación de Pymes en el espacio rural y en la inversión en infraestructura turística. El segundo, en apoyar mejora de los municipios rurales ${ }^{29}$. De hecho, el análisis de los proyectos aprobados subraya la importancia que tiene en estos programas la obra civil pública, que acapara alrededor del 80\% de la inversión realizada ${ }^{30}$.

El análisis de la ejecución de los programas de desarrollo deja en evidencia la falta un plan preconcebido. Son programas dirigidos a cubrir demandas puntuales de determinados municipios, preferentemente dirigidas a promover vivienda y obra urbana. El último programa aprobado, el correspondiente al periodo 2014-2020, pretende impulsar la estrategia recogida en los PDR y dar más importancia a los grupos de dinamización, pero éste también era objetivo de los anteriores y los resultados han sido muy discutibles.

Se ha de redirigir la demanda, sea pública o privada, hacia una estrategia común, una estrategia que priorice los ámbitos de actuación fundamentales; desarrollo agrario, promoción de actividades económicas acordes con las características del medio y acciones en materia de calidad de vida. Y atender estas necesidades supone implicar también a otros, especialmente otras administraciones, o de lo contrario las medidas adoptadas y las acciones ejecutadas carecerán, como ha ocurrido en los anteriores programas, de recorrido.

El modelo de proceder es el adecuado, seguramente el único posible, y aplicable a otros territorios y regiones. Pero la administración ha de creer en él y ha de dotarlo de contenido organizativo y presupuestario. Y lo ha de hacer a dos niveles diferentes. En primer lugar, la coordinación supramunicipal, provincial o regional, ha de ser una realidad y han de crearse mesas de discusión a este nivel para discernir aspectos relativos a la atención social, sanitaria, residencial, económica.... de las comunidades rurales. Pero también a nivel local. La organización comarcal es una escala adecuada pero ha de ser más abierta y participativa, aunque ello suponga un esfuerzo de coordinación importante, y ha de ser operativa, capaz de mostrar que las demandas de sus participantes obtienen una respuesta.

\section{CONCLUSIONES}

La decisión del Gobierno Vasco de impulsar un modelo de desarrollo rural supone un hito en la política rural Española reciente. La Comunidad apenas se beneficia de ayudas europeas y las líneas que marca no son suficientes para limitar las diferencias económicas y sociales entre el medio rural y el urbano. Las acciones de promoción económica del medio rural por si solas son insuficientes para asentar población, objetivo priorizado en estos programas, si no van acompañadas de promoción de vivienda, educación, infraestructura, atención social... Las instituciones vascas así parecen entenderlo y con este objeto diseñan herramientas y organización y se apoyan en la comarca como unidad de acción.

El modelo elegido no pasa desapercibido y pronto otras Comunidades e incluso la promulgación de la Ley 45/2007 del Gobierno de España para el desarrollo sostenible del medio rural estable las bases de una nueva política rural propia apoyada en la colaboración local y en la elaboración de un Plan de Zona, unidad equiparable a la comarca.

28 Programas habituales, impulsados por la Comunidad Europea y cofinanciados por las administraciones regionales, con unas líneas y objetivos que apenas difieren de unas comunidades a otras. Sirva como ejemplo el caso de una comunidad vecina al País Vasco, La Rioja, con dos ejes prioritarios dirigidos al desarrollo rural en el PDRs 2007-2013, el tercero, mejora de la calidad de vida de las zonas rurales y fomento de la diversificación de la actividad económica, y el cuarto, el enfoque líder, impulsando unas líneas similares a las del ejemplo en estudio (Nagore, 2007), ejes que, cambiada su numeración, se mantienen en el periodo 2014-20 (Pascual, 2015)

29 Alrededor de dos tercios del presupuesto se destina a financiar la construcción de vivienda, a acometer obras de urbanización de cascos urbanos y polígonos residenciales de nueva construcción, dotación de gas natural y pavimentación de accesos. Si a éstos añadimos aquellos dirigidos a dotar a los cascos rurales de servicios públicos y a mejorar y adecuar el patrimonio público para que sea visitable llegamos a la conclusión de que el apoyo a la iniciativa privada es reducido, inferior en todos los casos al $20 \%$ de presupuesto subvencionado. Si se desea profundizar en la direccionalidad de las inversiones realizadas mediante el programa Leader y el programa Erein en el País Vasco recomendamos consultar Alberdi (2006).

30 En el País Vasco, al igual que ocurre con otros grupos de acción local, la presencia institucional es muy importante y puede ser transcendental para asegurar la puesta en marcha de determinados proyectos. Pero el dominio de instituciones locales en muchas de ellas se evidencia en la tipología de proyectos presentados y aprobados posteriormente por la administración competente, dominando la iniciativa pública. Algunos investigadores incluso llegan a considerar al partenariado de estas asociaciones como ficticio, con alcaldes y representantes políticos que controlan las Juntas de estos grupos (Navarro, et al., 2014) aunque otros consideran la iniciativa Leader como una nueva forma de plantear el desarrollo fundamentado en la participación local (Nieto y Cárdenas, 2015) 
Estos nuevos marcos legales, sin embargo, no fructifican. Los precursores no desarrollan el contenido legal aprobado, los apoyados en el marco legal español (Castilla- La Mancha, Aragón, Rioja) realizan sus Planes de Zona pero sus contenidos, por la falta de un apoyo presupuestario que no llega, no se materializan y estos programas se abandonan.

La comarca, la zona, base del desarrollo local, queda vaciada de contenido y posibilidad. La exigencia del programa Leader de un Plan de Desarrollo Comarcal a cada uno de sus grupos de acción se mantiene también para el periodo 2014-2020. Como consecuencia cada zona elabora un diagnóstico y renueva los retos a lograr en el nuevo periodo. Pero la capacidad de acción del grupo se circunscribe a las posibilidades del programa, generalmente el apoyo a medidas que potencian la actividad económica local, y no cubre las necesidades que un desarrollo integral del territorio requiere. A pesar de las recomendaciones realizadas las últimas décadas, las demandas requeridas no se cumplen y los espacios rurales continúan requiriendo acciones dotacionales que permitan el progreso social de sus comunidades.

La situación en el País Vasco es, teóricamente, distinta. A diferencia de otros territorios, cuenta con un marco legal propio, independientemente del programa Leader (sólo tiene un grupo para todo el territorio), renueva sus 18 planes comarcales, establece medidas de control anual y potencia un funcionamiento peculiar.

Al plantear el objetivo de la investigación se proponía testar la validez y la evolución del patrón de desarrollo rural vasco. De su análisis deducimos que se trata de un ejemplo apoyado en dos pilares fundamentales: la transversalidad de sus acciones, es decir, potenciar actuaciones económicas, pero también servicios públicos, dotaciones, sociales y culturales; un modelo ligado al territorio, de abajo a arriba, apoyado en la Comarca como entidad local. Es un modelo sustentado en la experiencia de más de tres décadas de funcionamiento y basado en la tradición participativa Comunitaria.

Si la conveniencia del patrón no es cuestionable la situación esperada que preveía una vulgarización del modelo tampoco lo es. La anunciada transversalidad, al no reunirse los órganos de gestión territoriales (Landas), no se ha cumplido, la apuesta por la participación local se ha ido diluyendo hasta concretarse en un número reducido de personas y la única herramienta con la que estos grupos han contado han sido unos fondos comunitarios cuyos criterios venían establecidos de arriba abajo, es decir, el Departamento de Desarrollo Rural del País Vasco es el que decide lo que se ha de financiar y como ha de hacerse. Las diferencias con otros grupos de acción local son cada vez menores y el ejemplo vasco se convierte en uno más dentro de las regiones españolas y europeas.

La mayor peculiaridad de los grupos de acción local del País Vasco se sustenta en su micro-territorialización. Está conformado por un único grupo Leader, subdividido en 18 comarcas de unos $350 \mathrm{~km},{ }^{2}$ cada una con su PDR y grupo de acción local. Ello le aporta una mayor ligazón al territorio y un mayor contacto con sus actores, públicos y privados, rurales y urbanos, y un presumible mayor apoyo municipal e incluso provincial, pero no regional ni ligado a los programas de desarrollo rural.

Las hipótesis parciales planteadas también parecen cumplirse. La metodología, consecuencia de la experiencia y las posibilidades de acción, lleva a concretar voluntades y también participantes. Cada nueva revisión de los Planes de Desarrollo Rural en el País Vasco supone un esfuerzo por adecuar sus posibilidades a la situación del momento, una pretensión de materializar herramientas cada vez más realistas y funcionales. La última exploración apuesta por dar preferencia a los grupos de trabajo y a las propuestas del Plan Anual, inclusive la administración sectorial se compromete a apoyar estos contenidos. Pero, al igual que las anteriores, esta última propuesta es una sugerencia que depende de la decisión de una única administración, el Departamento de Desarrollo Rural, y es posterior a un marco de financiación ya establecido y difícilmente amoldable a la necesidad que cada territorio plantea.

Las demandas de los diferentes PDR tampoco han variado. Los objetivos y las propuestas se repiten programa a programa, aunque parece denotarse una mayor preocupación por las deficiencias dotacionales (vías de comunicación, atención social, escuela rural, ambulancia....) y por el abandono de la agricultura, generalizado ya en todo el territorio.

Finalmente nos cuestionábamos la validez del modelo vasco como herramienta de desarrollo rural. En la investigación se llega a la conclusión de que se trata de un modelo adecuado a la realidad territorial y competencial de la Comunidad Autónoma del País Vasco puesto que es capaz de integrar el ámbito municipal, provincial y regional. 
También es conveniente la conjunción urbano-rural de su estructura comarcal puesto que los urbanos también tienen medio rural y/o se benefician de él. Es importante su colaboración en el progreso de los espacios rurales de proximidad y se acierta en la micro-territorialización propia de este entorno.

Igualmente, se acierta en los pilares en los que se sustenta el documento legal, la transversalidad de las acciones y el enfoque bottom up. La estructura organizativa propuesta es la adecuada y aplicable, salvando las peculiaridades vascas, a otros territorios.

Pero para que el patrón pueda funcionar ha de ser revisado el contenido legal y dotar de mayor presencia y obligatoriedad a las Landas Territoriales y a Landaberri, como órganos que garantizan la transversalidad requerida y como entidades capaces de satisfacer las demandas que desde las comarcas son propuestas.

\section{REFERENCIAS}

Alario, M. y Baraja, E. (2006). Políticas públicas de desarrollo rural en Castilla y León, ¿sostenibilidad consciente o falta de opciones? LEADER II. Boletín de la Asociación de Geógrafos Españoles. 2006, (41), 267-293. Recuperado de: http://boletin.age-geografia.es/articulos/41/11POLITICAS\%20PUBLICAS.pdf

Alberdi, J.C. (2004). Colaboración interinstitucional en el desarrollo rural: aciertos y fracasos de la Ley de Desarrollo Rural del País Vasco. Boletín de la Asociación de Geógrafos Españoles, (33), 7-30. Recuperado de: http://www.age-geografia.es/ojs/index.php/bage/article/view/486

Alberdi, J.C. (2006). El pequeño municipio, articulador de la política de desarrollo rural del País Vasco: el ejemplo de Guipúzcoa, Xeográfica, (5), 7-31. Recuperado de: https://minerva.usc.es/xmlui/bitstream/ handle/10347/3746/P\%C3\%Alginas\%20desdeXEOGRAFICA_6_2006-1.pdf?sequence=1

Alberdi, J.C. (2010). Experiencia, pragmatismo y líneas de actuación comunes, bases del nuevo modelo de desarrollo rural del País Vasco. Estudios Geográficos, (268), 7-38. http://dx.doi.org/doi:10.3989/ estgeogr.0433

Andrés, J.L. (2010). Conocimientos tácitos y desarrollo rural. Aportaciones a la aplicación del programa de desarrollo rural de Aragón 2007-2013. Xiloca,(38), 31-54. Recuperado de: http://www.xiloca.org/ data/Bases\%20datos/Xiloca/X_38_31.pdf

Asociación de Desarrollo Rural Añana (2016). Programa de Desarrollo Rural Comarcal 2015-2020. ADR Añana, Hazi, Gobierno Vasco. Recuperado de: http://www.valdegovia.org/fotos/PDR\%20Valles\%20 Alaveses\%2014\%20de\%20diciembre\%202015.pdf

Bristow, G. Cowwell, R \& Marsden, T. (2001). Tensions, limits and potentials. Evaluating rural development policies in Scotland. European Urban and Regional Studies, (8), 235-252. http://dx.doi.or g/10.1177/096977640100800305

Cáceres, J. (1996). Ejes de desarrollo de los planes comarcales de montaña catalanes. VIII Coloquio de Geografía Rural . Asociación de Geógrafos Españoles, Jaca, 3-14.

Casley, D. J. y Kumar K. (1990). Recopilación, análisis y uso de los datos de seguimiento y evaluación, Madrid, Ediciones Mundi-Prensa/Banco Mundial, 179 pág.

Cejudo, E y Navarro, F. (2003). El reparto territorial de los programas de desarrollo rural. El caso de la provincia de Granada. Anales de Geografía de la Universidad Complutense, (23), 131-162. Recuperado de: http://revistas.ucm.es/index.php/AGUC/article/view/AGUC0303110131A

Cejudo, E. y Navarro, F. (2009). La inversión en los programas de desarrollo rural: su reparto territorial en la provincia de Granada. Anales de Geografía de la Universidad Complutense, Vol. 29, (2), 37-64. Recuperado de: http://revistas.ucm.es/index.php/AGUC/article/view/31902

Corbera, M. (1999). Las políticas de desarrollo rural en la región Cantábrica: los programas LEADER. Cambios en los Espacios Rurales Cantábricos tras la integración de España en la UE. Universidad de Cantabria, 175-237.

Cruz Orozco, J. (1996). Desarrollo rural y políticas públicas en las zonas de montaña del País Valenciano. VIII Coloquio de Geografía Rural. Asociación de Geógrafos Españoles , Jaca, 53-68.

Gil de Arriba, C. (1998). Programas Europeos y desarrollo rural en Cantabria. Actuaciones y perspectivas. Polígonos, (8), 39-51. Recuperado de: https://repositorio.unican.es/xmlui/handle/10902/3064 
Esparcia, J. Noguera, J. (2000). Aproximación teórico-metodológica a la cultura evaluativa y la evaluación de programas de desarrollo rural. Cuadernos de Geografía Universidad de Valencia, (67-68), 77-101. Recuperado de: http://roderic.uv.es/handle/10550/31226

Esparcia, J. (2014). Innovation and networks in rural areas. An analysis from European innovative projects. Journal of Rural Studies,(34), 1-14. http://dx.doi.org/10.1016/j.jrurstud.2013.12.004

García, J. y Rodríguez, P. (2004). Rompiendo Distancias: Un programa integral para prevenir y atender la dependencia de las personas mayores en el medio rural, Rev. Española de Geriatría y Gerontología, Vol. 40 (1), 22-33

Gobierno de Aragón (2011). Plan de zona de desarrollo rural sostenible de la comarca del Bajo AragónCaspe. Gobierno de Aragón. 294 p. Recuperado de: http://www.aragon.es/estaticos/ImportFiles/BAJO ARAGON_CASPE/ISA_BAJO_ARAGON-CASPE_+_ANEXOS.pdf

Gobierno de Castilla-León (2011). Programa de desarrollo rural sostenible. Plan de zona rural Ávila Norte (2010-2014). Junta de Castilla-León. 305 p. Recuperado de: http://www.jcyl.es/jcyl/ concentracionparcelaria/2avilanorteB.pdf

Gobierno de La Rioja (2011). Programa de desarrollo rural sostenible. Gobierno de La Rioja. 361 p. Recuperado de: http://www.larioja.org/agricultura/es/desarrollo-rural/desarrollo-rural-sostenible/ planes-zona.ficheros/600359-668610_PLAN_DE_ZONA_CAMEROS_web_.pdf

Gobierno de Navarra (2003). Ley Foral 17/2003, de 17 de marzo, de Desarrollo Rural de Navarra. Boletín Oficial de España. 99, p. 10102-10106. Recuperado de: https://www.boe.es/boe/dias/2003/04/25/pdfs/ A16102-16108.pdf

Gobierno Vasco. Departamento de Agricultura y Pesca (1985). Decreto 394/1985, de 30 de Diciembre de 1985 sobre Régimen específico de la Agricultura de Montaña en la Comunidad Autónoma del País Vasco. Boletín Oficial del País Vasco. 1986032. Recuperado: www.irekia.euskadi.eus/es/ orders/198600410? track=1

Gobierno Vasco. Departamento de Desarrollo Rural (1998). Ley 10/1998 de Desarrollo Rural. Boletín Oficial del País Vasco. 80. Recuperado de: http://noticias.juridicas.com/basedatos/CCAA/pv-110-1998.html

Gobierno Vasco. Departamento de Agricultura, Pesca y Alimentación (2014). Programa de Desarrollo Rural del País Vasco 2007-2013. Vitoria, 803 pag. Recuperado: http://www.mapama.gob.es/es/desarrollorural/temas/programas-ue/PDR_Pais_Vasco_v10_tcm7-151349.pdf

Guber, R. (2001). La etnografía, método, campo y reflexividad. Bogotá: Grupo Editorial, Norma.

Guerrero, L.M. (2014). La entrevista en el método cualitativo. Recuperado de: http://rehue.csociales. uchile.cl/genetica/cgo4.htm

Hazi (2016). Programas de Desarrollo Rural del País Vasco 2015-2020. Departamento de Desarrollo y Competitividad del Gobierno Vasco. Recuperado de: http://www.nasdap.ejgv.euskadi.eus/informacion/ programas-de-desarrollo-rural-comarcales-2015-2020/r50-5333/es/ [Fecha de última modificación 16/9/2016].

Marquardt, D. ,Möllers, J. \& Buchenrieder, G. (2012). Social Networks and Rural Development: LEADER in Romania. Sociologia Ruralis, (52), 398-431. http://dx.doi.org/10.1111/j.1467-9523.2012.00571.x

Mendikoi (1998). Plan de desarrollo rural de las comarcas de Montaña Alavesa, Valles Alaveses, Rioja Alavesa, Estribaciones del Gorbea, Cantábrica Alavesa, Llanada Alavesa, Enkarterrialde, Arratia Nervión, TolosaldeaUrola Kosta. Departemento de Agricultura del Gobierno vasco. Vitoria. Inédito (formato CD).

Mendikoi (2000). Plan de desarrollo rural de las comarcas de Durangaldea, Uribe, Busturialdea, Lea-Artibai, Debabarrena, Donostialdea, Goierri, Debagoiena. Departemento de Agricultura del Gobierno vasco. Vitoria. Inédito (formato CD).

Mendikoi (2003). Ley de Desarrollo Rural y Programas de Desarrollo Rural. Jornadas de reflexión 14,15,18 y 24 de Julio de 2003. Departamento de Agricultura del Gobierno vasco. Vitoria. Inédito.

Mendikoi (2007). Programas de Desarrollo Rural del País Vasco 2007-2013. Sociedad Pública del Gobierno Vasco. Fecha de Consulta 10/9/2016. Recuperado de: http://fpe.hazi.es/comunicacion/noticias/ noticiaMendikoi.asp? id=es\&Notici=268263158/

Mendinet (2015). Qué es Mendinet. Recuperado de: http://www.mendinet.org/ 
Ministerio de Agricultura, Pesca, Alimentación y Medio Ambiente (2007). Ley 45/2007 para el desarrollo sostenible del medio rural. Boletín Oficial del Estado. 229, p.18. Recuperado de: https://www.boe.es/ buscar/pdf/2007/BOE-A-2007-21493-consolidado.pdf

Murray, R. (2002). Citizens' Control of Evaluations: Formulating and Assessing Alternatives, Evaluation, vol. 8, (1), 81-100. http://dx.doi.org/10.1177/135890200200800148

Nagore, I. (2007). Programa de Desarrollo Rural de La Rioja (2007-2013), Cuaderno de campo, (36), 4-12.

Navarro, F., Cejudo, E y Maroto J.C. (2014): Reflexiones en torno a la participación en el desarrollo rural. ¿Reparto social o reforzamiento del poder? LEADER y PRODER en el sur de España. Eure, (121), 203-224. Recuperado de: http://www.redalyc.org/articulo.oa?id=19631675010

Nieto, A. y Cárdenas, G. (2015). El método Leader como política de desarrollo rural en Extremadura en los últimos 20 años (1991-2013), Boletín de la AGE, (69), 139-162. Recuperado de: http://boletin.agegeografia.es/articulos/69/06\%20BAGE69.pdf

Nogués, S. (2004) (ed.). El futuro de los espacios rurales. Santander: Servicio de Publicaciones de la Universidad de Cantabria

Oliva, J. e Iso A. (2014). Diseños metodológicos para la planificación participativa del paisaje, Empiria, revista metodológica de las ciencias sociales, (27), 65-112. http://dx.doi.org/10.5944/empiria.27.10864

Pascual, E. (2015). Programa de Desarrollo Rural 2014-2020, Cuaderno de campo, (56), 32-35. Recuperado de: http://www.larioja.org/larioja-client/cm/agricultura/images?idMmedia=600432

Patton, M. Q. (2002). A Vision of Evaluation that Strengthens Democracy, Evaluation, vol. 8, (1), $125-139$. Doi: http://dx.doi.org/10.1177/1358902002008001740

Plaza, J.I. (2005). Desarrollo y diversificación en las zonas rurales de España: el programa Proder. Boletín de la A.G.E. (39), 399-422.

Reder (2016). Propuesta para el reparto de los Fondos Feader. Red Estatal de Desarrollo Rural. Última actualización 13/11/2016. Recuperado de: http://www.redestatal.com/propuestas-para-el-reparto-delos-fondos-feader-2014-2020

Reinoso, D. y Sancho, J. (2002). Equipamientos y servicios en la Sierra Norte de Guadalajara: un diagnóstico basado en la participación social. X Coloquio de Geografía Rural. Asociación de Geógrafos Españoles. Santander, p. 772-779.

Sancho, J. y Reinoso, D. (2013). De la evaluación tradicional a la medición del impacto en los programas de desarrollo rural de la Unión Europea con especial referencia a Leader: Una primera aproximación, GeoFocus, (13), 212-230. Recuperado de: http://www.geofocus.org/index.php/geofocus/article/view/295

Sanz Hernández, A. (2001). Desarrollo rural. ¿Ocio o necesidad? 5campus. com. Recuperado de: http:// www.5campus.com/lección/desarural

Vidueira, P., Fernández, M. J. y Gallego, F. (2013). La facilitación del trabajo en grupo. Una apuesta para la sostenibilidad de los proyectos de desarrollo rural (en Cuenca). 17th International Congress on Project Management and Engineering . Logroño, 17-19th July 2013. Recuperado de: http://oa.upm. es/25916/1/INVE_MEM_2013_161681.pdf

Viñas, V. (2004). Evaluación cualitativa de programas de desarrollo regional en zonas rurales. Revista de estudios regionals, (71) 13-36. Recuperado de: http://www.redalyc.org/articulo.oa?id=75507101

Wellbrock, Roepa, Mahonb, Kairytec, Nienaberd, Domínguez, Kriszanf \& Farrellb (2013). Arranging public support to unfold collaborative modes of governance in rural areas. Journal of Rural Studies. (32) 420-429. http://dx.doi.org/10.1016/j.jrurstud.2013.10.002

Wojan, Tr. \& Rupasingha, A. (2001). Crisis as opportunity: local context, adaptive agents and the possibilities of rural development. Regional Studies, (35) 114-152. http://dx.doi.org/10.1080/00343400120033124 